\title{
Multiband Operation and Performance Enhancement of the PIFA Antenna by Using Particle Swarm Optimization and Overlapping Method
}

\author{
L. Wakrim, S. Ibnyaich, and M. M. Hassani \\ I2SP Team, Faculty of Science Semlalia, Marrakech, Morocco \\ Correspondence should be addressed to L. Wakrim; layla.wakrim@gmail.com
}

Received 9 November 2016; Revised 26 December 2016; Accepted 5 January 2017; Published 15 February 2017

Academic Editor: Baoding Liu

Copyright (C) 2017 L. Wakrim et al. This is an open access article distributed under the Creative Commons Attribution License, which permits unrestricted use, distribution, and reproduction in any medium, provided the original work is properly cited.

Recently, the demand for wireless devices that support multiband frequency has increased. The integration of such technology in mobile communication system has led to a great demand in developing small size antenna with multiband operation, which is able to operate in the required system. In this paper, a novel type planar inverted F antenna (PIFA) with gridded ground plane structure and overlapping cells is presented. By controlling the overlapping size, we improve the characteristics of the proposed antenna. This antenna is developed to achieve multiband operation with small size and good performance. The particle swarm optimization (PSO) is employed to a PIFA antenna to get rid of the limitations of single band operation by searching the optimal localization and length of linear slots on the ground plane to give triband operation. This PIFA antenna can be integrated to operate for several mobile applications as Bluetooth/WLAN, WIMAX, and 4G (UMTS2100, LTE). The optimized antenna is simulated by both Ansoft HFSS and computer simulation technology microwave studio (CSTMWS) in terms of S-parameters. A good agreement between simulated performances by both software types is achieved. A parametric study is made to analyze the effect of different PIFA parameters on the operating frequency and the reflection coefficient in order to enhance the antenna performances. In these frequency bands, the antenna has nearly omnidirectional radiation pattern.

\section{Introduction}

Currently, mobile handset antennas require characteristics such as compact size, wide bandwidth, and simple structure [1]. The planar antennas are a generation of antennas boasting the attractive features required; one of them is planar inverted F antenna (PIFA). Because of their small volume, thin profile, and ease of fabrication, PIFAs (planar inverted F antennas) have been shown to be a promising alternative to meet the requirements for mobile handset antennas [2, 3]. A PIFA operates at a resonant length of $\lambda / 4$; it is highly conducive to a small and lightweight design and suitable for use as an internal antenna [4].

There are several methods that have been proposed by previous papers to produce multiband operation. One of the most chosen methods are through adding parasitic element [5-7], inserting V-shaped slot on radiating element [8], and using meander-shaped radiator as mentioned in [9]. There are also other methods used to reach the same objective. For example, in [10], the multiband operation is achieved by comprising three top patches, by using S-shaped patch [11], by employing fractal method [12-14], and by introducing the slots on the ground plane [15-17].

Therefore, the technique used in this paper to obtain triband PIFA antenna is by combining the use of slots on the ground plane and the particle swarm optimization (PSO). Recently, the PSO technique has been successfully applied to the design of antennas and microwave components. The results proved that this method is powerful and effective for optimization problems [18].

The purpose of adding slots on the ground plane is to achieve a triband operation, and the objective of using particle swarm optimization is to determine the width and the localization of each slot on the ground plane which helps to obtain multiband operation. 
This paper presents a triband PIFA antenna operating at UMTS2100 (1.92-2.17 GHz), LTE 2300/2600 (2.3-2.4 GHz/ 2.50-2.69 GHz), Bluetooth/WLAN (2.4-2.48 GHz/5.72$5.82 \mathrm{GHz})$, and WIMAX $(2.5-2.8 \mathrm{GHz})$.

This paper is divided into four sections. Section 1 is an introduction. Section 2 presents the antenna structure and methodology. Section 3 is devoted to the discussion of the simulation and results and the last section is a conclusion of the study.

\section{Antenna Structure and Methodology}

2.1. Particle Swarm Optimization Overview. The PSO algorithm is an evolutionary algorithm capable of solving difficult multidimensional optimization problems in various fields. Figure 1 shows the flowchart of a PSO algorithm.

As an evolutionary algorithm, the PSO algorithm depends on the social interaction between independent particles, during their search for the optimum solution. The initial population of particles is randomly generated. Each particle represents a potential solution and has a position represented by a position vector $\overrightarrow{x_{i}}$. A swarm of particles moves through the problem space, with the moving velocity of each particle represented by a velocity vector $\vec{v}_{i}$. Each particle keeps track of its own best position, which is associated with the best fitness it has achieved so far in a vector $\vec{p}_{i}$. Furthermore, the best position among all the particles obtained so far in the population is kept track of as $\overrightarrow{p_{g}}[19]$. The particle's velocity update and position update are the main PSO operators, which can be expressed as [20-22]

$$
\begin{aligned}
\vec{v}_{i}(\tau+1)= & \omega \vec{v}_{i}(\tau)+c_{1} \gamma_{1}\left(\vec{p}_{i}(\tau)-\vec{x}_{i}(\tau)\right) \\
& +c_{2} \gamma_{2}\left(\overrightarrow{p_{g}}(\tau)-\vec{x}_{i}(\tau)\right), \\
\vec{x}_{i}(\tau+1)= & \vec{x}_{i}(\tau)+\vec{v}_{i}(\tau+1),
\end{aligned}
$$

where $c_{1}$ and $c_{2}$ are acceleration constants and $\gamma_{1}$ and $\gamma_{2}$ are uniformly distributed random numbers in $[0,1]$. The term $\overrightarrow{v_{i}}$ is limited to its bounds. If the velocity violates this limit, it is set to its proper limit. $\omega$ is the inertia weight factor and in general, it is set according to the following equation:

$$
\omega=\omega_{\max }-\frac{\omega \max -\omega \min }{T} \cdot \tau,
$$

where $\omega_{\max }$ and $\omega_{\min }$ are maximum and minimum value of the weighting factor, respectively. $T$ is the maximum number of iterations and $\tau$ is the current iteration number.

2.2. PIFA Antenna Parameters. Figure 2 depicts the geometry of the proposed triband PIFA antenna. The ground plane has dimensions of $W_{g} \times L_{g} \times t_{g}$; the material used is FR4 substrate with a dielectric constant of 4.4 and a tangent loss of 0.02 . The radiating plate, the copper, with a rectangular shape has dimensions of $W_{p} \times L_{p} \times t_{p}$. The antenna height is $h$ and the space between the radiating plate and the ground plane is filled with air. The shorting plate's dimensions are $W_{s} \times L_{s} \times t_{s}$ and the feeding plate's dimensions are $W_{f} \times L_{f}$. It should also

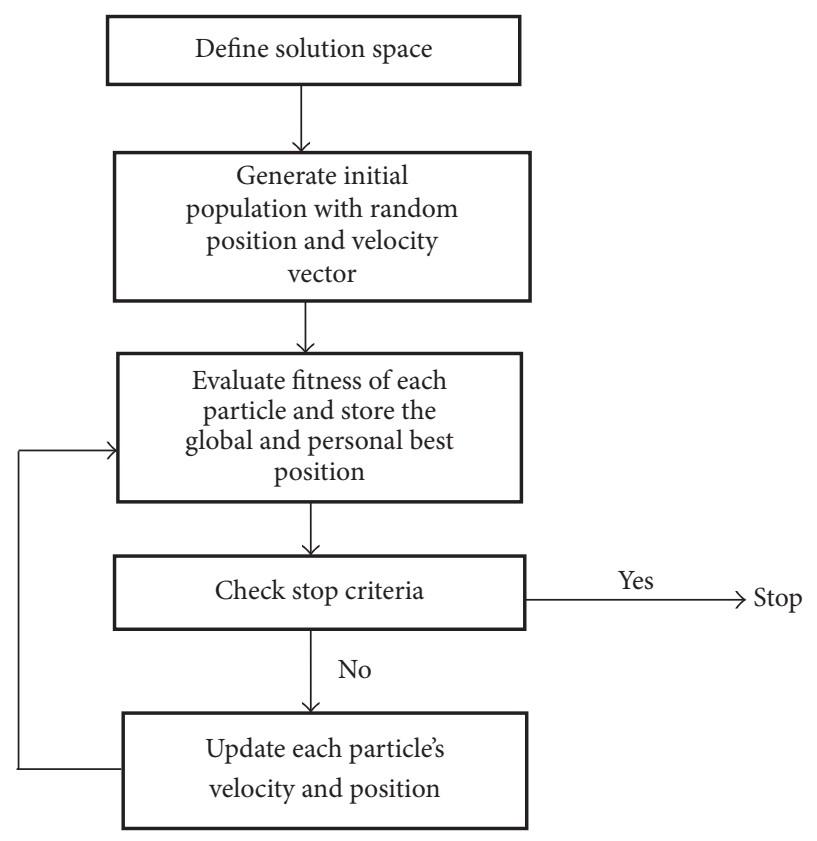

FIGURE 1: Flowchart of a PSO algorithm.

TABle 1: Antenna parameter's dimension.

\begin{tabular}{lc}
\hline Parameters & Dimension in $\mathrm{mm}$ \\
\hline$W_{p}$ & 24 \\
$L_{p}$ & 37 \\
$t_{p}$ & 0.2 \\
$L_{g}$ & 41 \\
$W_{g}$ & 40 \\
$t_{g}$ & 0.5 \\
$W_{s}$ & 3 \\
$L_{s}$ & 2.8 \\
$t_{s}$ & 0.2 \\
$h$ & 2.3 \\
$W_{f}$ & 2 \\
$L_{f}$ & 0.5 \\
\hline
\end{tabular}

be noted that the antenna is fed by a $50 \Omega$ microstrip line. Table 1 summarizes the antenna parameters with dimensions in $\mathrm{mm}$.

In this study, particle swarm optimization (PSO) is used to determine the slots location and widths in order to achieve multiband PIFA antenna. The ground plane area is divided into $7 \times 8$ small cells where each cell can be assigned either conducting or nonconducting properties. The size of a cell is taken equal to $5 \times 5 \mathrm{~mm}^{2}$ in order to achieve better results.

The ground plane is fragmented into 56 cells along the $y$ axis with $1 \mathrm{~mm}$ of overlapping between parallel cells in order to find the best solution of conducting cells. Because there are only two possible values, binary coding is used. If a cell is existing, then the corresponding gene is assigned " 1 " and if a cell is nonexisting, the gene takes the " 0 " value and it is considered as slot. 


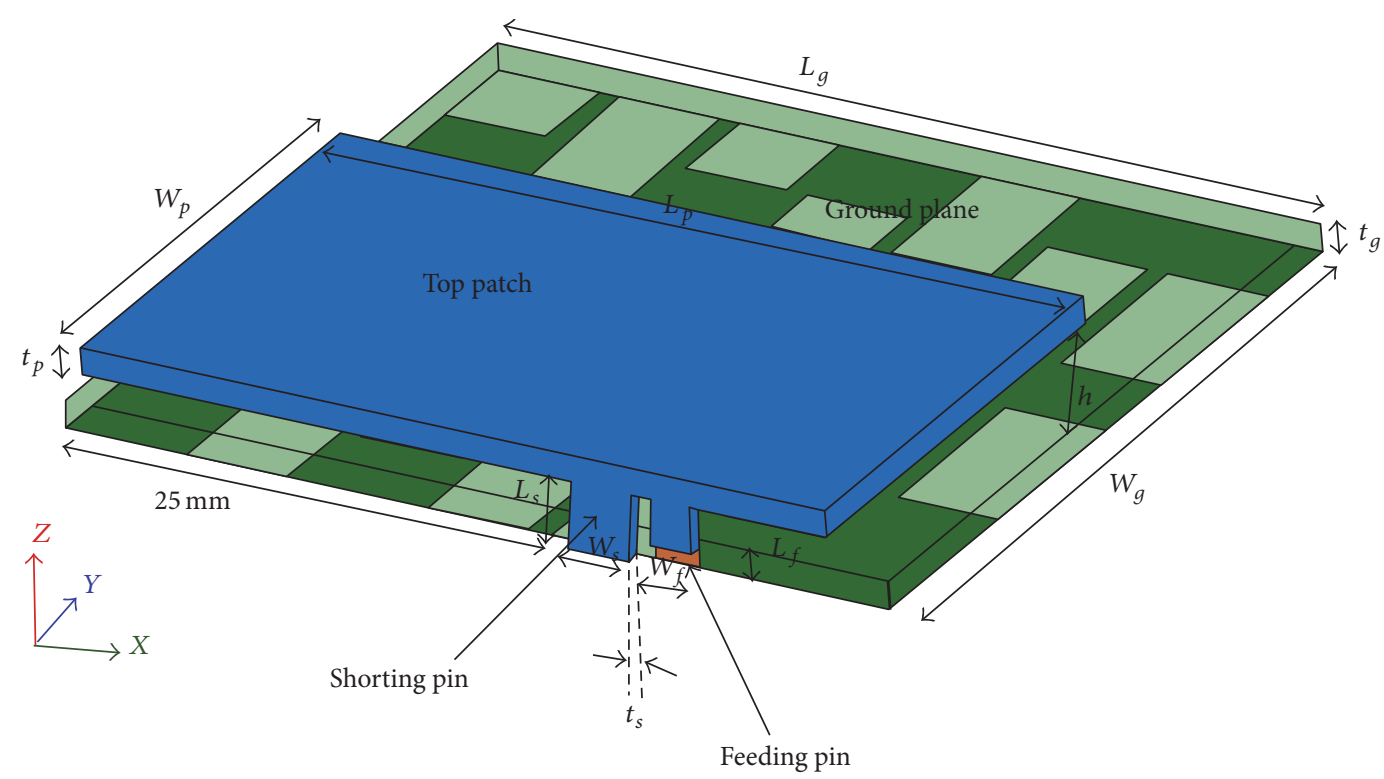

FIgURE 2: The geometry of the proposed triband PIFA structure.

The fitness function is the summation of reflection coefficient values from 2 to $6 \mathrm{GHz}$ band's frequencies. The fitness function $F$ which is minimized in the search for the optimum solution is written as

$$
F=\sum \frac{S_{11}(f(i))}{10 N}
$$

where $f(i)$ is the sampling frequency, $N$ is the number of the sample, and $S_{11}$ is the reflection coefficient.

Our aim is to find an optimized ground plane with PSO that achieves a reflection coefficient less than $-10 \mathrm{~dB}$ in the frequency bands from 2 to $6 \mathrm{GHz}$.

The PSO operates on a matrix chromosome, which describes the shape of the ground plane. This chromosome design is described in Figure 3(a). Matrix cells which contain a 1 correspond to portions of the antenna ground plane filled with metal; cells which contain a 0 correspond to portions of the antenna that are not filled.

In this proposed design of triband PIFA antenna, the ground plane contains 14 slots that are overall located in its surface as shown in Figure 3(b); all slots have the same length but different width. Table 2 indicates the size of each slot in $\mathrm{mm}$.

\section{Simulation Results and Discussion}

In this section, all the simulation results for triband PIFA for UMTS2100 (1.92-2.17 GHz), LTE 2300/2600 (2.32.4 GHz/2.50-2.69 GHZ), Bluetooth/WLAN (2.4-2.48 GHz/ $5.72-5.82 \mathrm{GHz})$, and WIMAX $(2.5-2.8 \mathrm{GHz})$ will be presented in detail.

3.1. Reflection Coefficient $S_{11}$. The optimized PIFA designed by PSO was simulated using HFSS and CST microwave
TABLE 2: Slots parameters.

\begin{tabular}{lccccc}
\hline Slot numbers & $1,2,6,7,9$ & 3 & $4,8,10,11$ & 12 & $5,13,14$ \\
\hline $\begin{array}{l}\text { Dimension in } \\
\mathrm{mm}^{2}\end{array}$ & $5 \times 5$ & $5 \times 20$ & $5 \times 15$ & $5 \times 30$ & $5 \times 10$ \\
\hline
\end{tabular}

studio. Its reflection coefficient variations with frequency are shown in Figure 4.

The optimized antenna clearly resonates in three frequency bands $(2.14,3.18$, and $5.95 \mathrm{GHz})$ given by CST simulator. For HFSS software, we found 2.21, 2.89, and $5.58 \mathrm{GHz}$, which cover the partially $3 \mathrm{G}$ and $4 \mathrm{G}$ bands. Good agreement is observed between HFSS and CST results. We can remark that the value of $S_{11}$ is lower than $-10 \mathrm{~dB}$, the bandwidth is more than $10 \%$ for the three bands, and thus, the antenna is considered as a wide band. Table 3 summarizes the PIFA characteristics in terms of resonant frequency, reflection coefficient, and bandwidth by both HFSS and CST software.

3.2. Radiation Patterns. The radiation patterns simulated by HFSS at $x z$ plane $\left(\varphi=0^{\circ}\right)$ and $y z\left(\varphi=90^{\circ}\right)$ plane for the three resonant frequencies are represented in Figure 5. It can be observed that this antenna has a nearly omnidirectional pattern. The antenna gain is about $4.17,2.21$, and $5.61 \mathrm{~dB}$ for the frequencies of $2.21,2.89$, and $5.58 \mathrm{GHz}$, respectively.

\subsection{Parametric Study}

3.3.1. Overlapping Size Effect. It is evident that PIFA characteristics are affected by a number of ordinary parameters such as the top patch size $\left(L_{p}\right.$ and $\left.W_{p}\right)$, ground plane size $\left(W_{g}\right.$ and $\left.L_{g}\right)$, shorting plate width $\left(W_{c}\right)$, height of antenna $(h)$, and the localization of shorting and feeding plate. The rationale 


\begin{tabular}{|c|c|c|c|c|c|c|c|}
\hline 1 & 1 & 1 & 1 & 0 & 1 & 1 & 0 \\
\hline 0 & 0 & 0 & 0 & 1 & 0 & 0 & 0 \\
\hline 1 & 0 & 0 & 1 & 1 & 0 & 1 & 0 \\
\hline 0 & 0 & 0 & 1 & 1 & 1 & 0 & 1 \\
\hline 0 & 0 & 0 & 1 & 1 & 0 & 0 & 0 \\
\hline 1 & 0 & 0 & 0 & 0 & 0 & 0 & 1 \\
\hline 1 & 1 & 0 & 0 & 1 & 0 & 0 & 1 \\
\hline
\end{tabular}

(a)

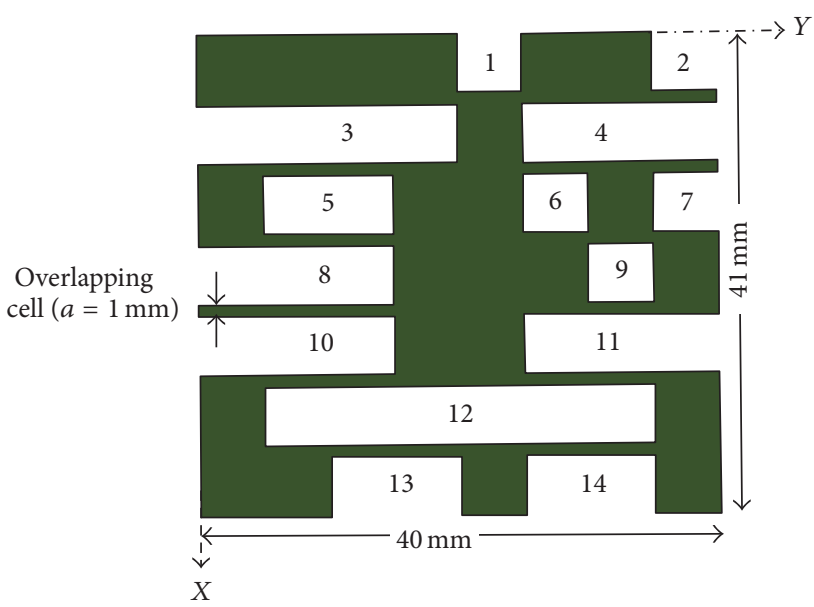

(b)

FIgURE 3: (a) Chromosome matrix. (b) A front view of the ground plane.

TABLE 3: PIFA characteristics.

\begin{tabular}{|c|c|c|c|c|c|}
\hline \multicolumn{3}{|c|}{ HFSS } & \multicolumn{3}{|c|}{ CST } \\
\hline $\begin{array}{l}\text { Resonant } \\
\text { frequency }(\mathrm{GHz})\end{array}$ & $\begin{array}{c}\text { Reflection } \\
\text { coefficient } S_{11}(\mathrm{~dB})\end{array}$ & Bandwidth (\%) & $\begin{array}{c}\text { Resonant } \\
\text { frequency }(\mathrm{GHz})\end{array}$ & $\begin{array}{l}\text { Reflection coefficient } S_{11} \\
(\mathrm{~dB})\end{array}$ & $\begin{array}{c}\text { Bandwidth } \\
(\%)\end{array}$ \\
\hline 2.21 & -24.21 & 18.55 & 2.14 & -35.81 & 18.69 \\
\hline 2.89 & -36.25 & 30.10 & 3.18 & -28.16 & 21.38 \\
\hline 5.58 & -21.03 & 23.11 & 5.95 & -26.83 & 22.68 \\
\hline
\end{tabular}

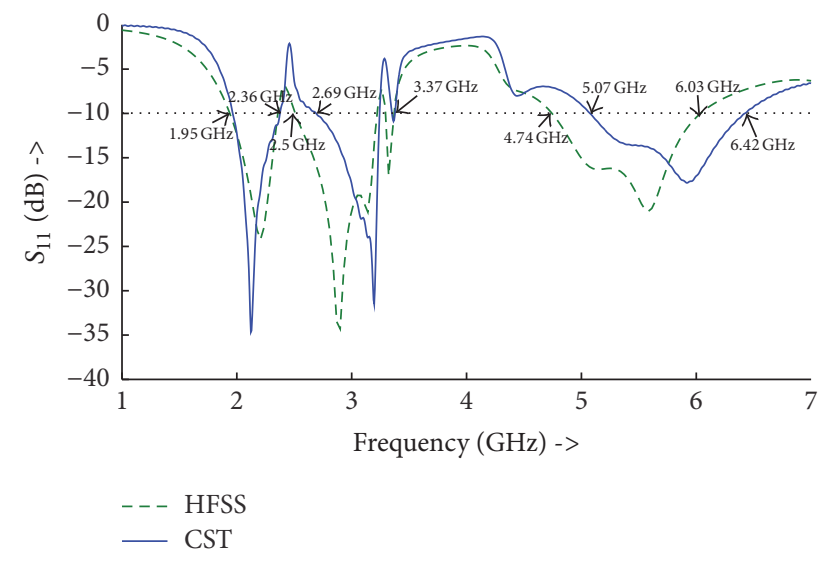

FIGURE 4: Simulated reflection coefficient (HFSS and CST).

of the parametric study of our optimized PIFA antenna is to improve its characteristics by using HFSS.

In this study, a new parameter which is the overlapping size between parallel cells will be analyzed. The overlap size should be large enough to be compatible for a fabrication process and to contact neighboring cells properly. On the other hand, the overlap size should be small enough to have nonconducting regions on the ground plane area. Therefore, three different overlap sizes $(0.5 \mathrm{~mm}, 1.5 \mathrm{~mm}$, and $2 \mathrm{~mm})$ have been investigated as shown in Figure 6.

The PIFA antenna with an overlap of $0.5 \mathrm{~mm}$ exhibits the three bands (1938 MHz to $2313 \mathrm{MHz}, 2500 \mathrm{MHz}$ to $3172 \mathrm{MHz}$, and $4973 \mathrm{MHz}$ to $6118 \mathrm{MHz}$ ). Therefore, this PIFA is suitable for UMTS2100, LTE2600, lower band WIMAX (2.5$2.8 \mathrm{GHz}$ ), and WLAN. However, when compared to the PIFA with $1 \mathrm{~mm}$ overlapping we notice that the bandwidth has been affected.

The PIFA antenna with an overlap of $1.5 \mathrm{~mm}$ resonates from $1959 \mathrm{MHz}$ to $2302 \mathrm{MHz}, 2536 \mathrm{MHz}$ to $3408 \mathrm{MHz}$, and $4830 \mathrm{MHz}$ to $6241 \mathrm{MHz}$. The results show that the bandwidth of the upper resonant frequency is larger and the reflection coefficient is improved. This PIFA shows triband performance covering UMTS2100, LTE2600, lower band WIMAX, partial middle band WIMAX, and WLAN. When the overlap is increased to $2 \mathrm{~mm}$, the PIFA antenna resonates from $2064 \mathrm{MHz}$ to $2492 \mathrm{MHz}$ and $2614 \mathrm{MHz}$ to $3318 \mathrm{MHz}$. It covers Bluetooth/WLAN, LTE2300, and middle band WIMAX. We observe that the lower resonant frequency is shifted and the bandwidth is decreased representing only dual band antenna. The overlapping size of $1.5 \mathrm{~mm}$ represents the most suitable value for this design.

3.3.2. Patch Length's Effect. Figure 7 shows three different lengths of the patch $\left(L_{p}\right)$ that are simulated and compared with the length of the proposed antenna $\left(L_{p}=37 \mathrm{~mm}\right)$. The patch length has been changed while the other parameters were kept constant to find out its effects on the variation of reflection coefficient of the PIFA antenna. The results reveal that when the length $\left(L_{p}\right)$ is increased to $41 \mathrm{~mm}$, the upper band is shifted. When the $L$ is lower than $37 \mathrm{~mm}$ the frequency range in all bands is decreased and its reflection 


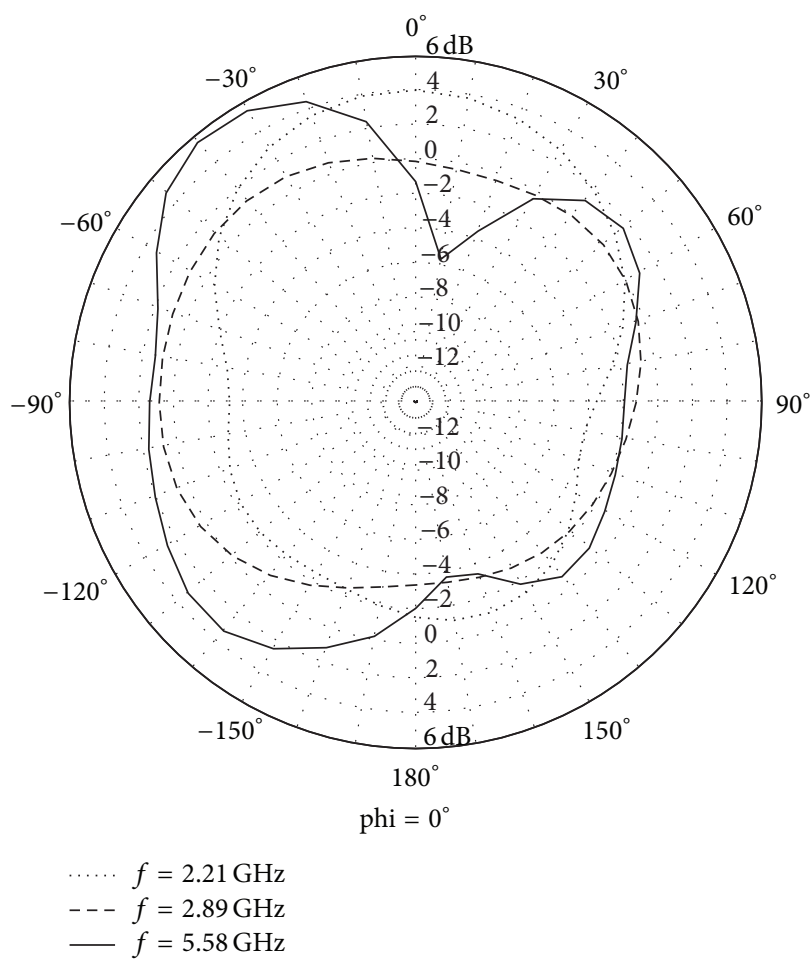

(a)

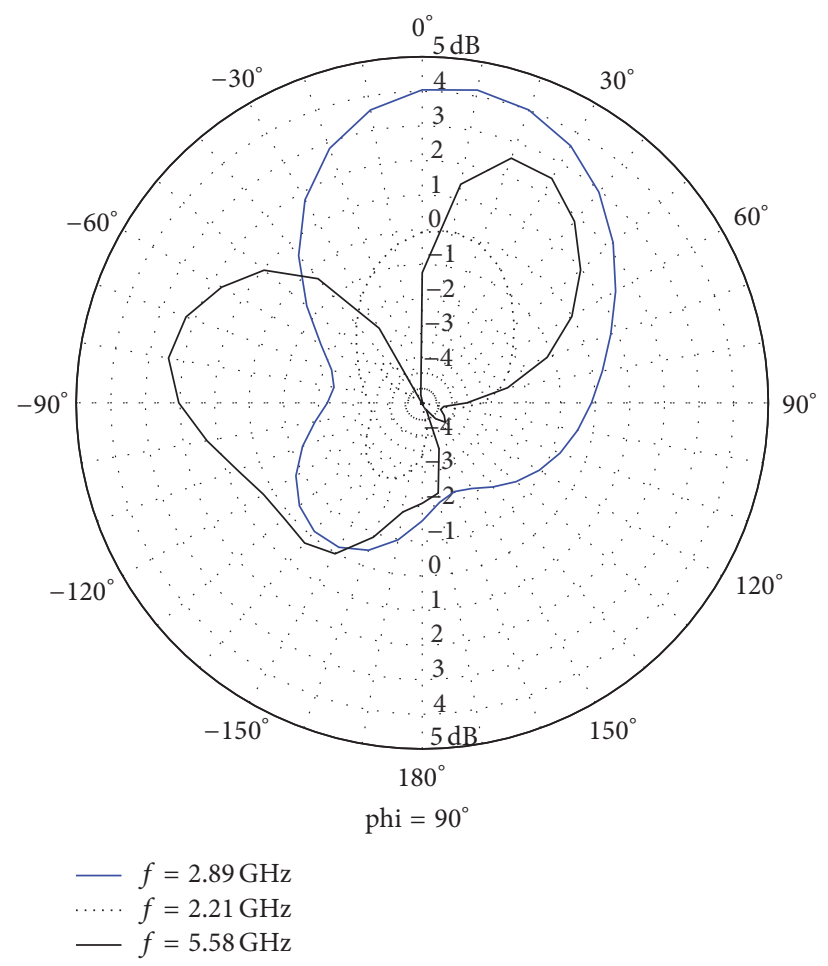

(b)

FIgURE 5: Simulated 2D radiation patterns.

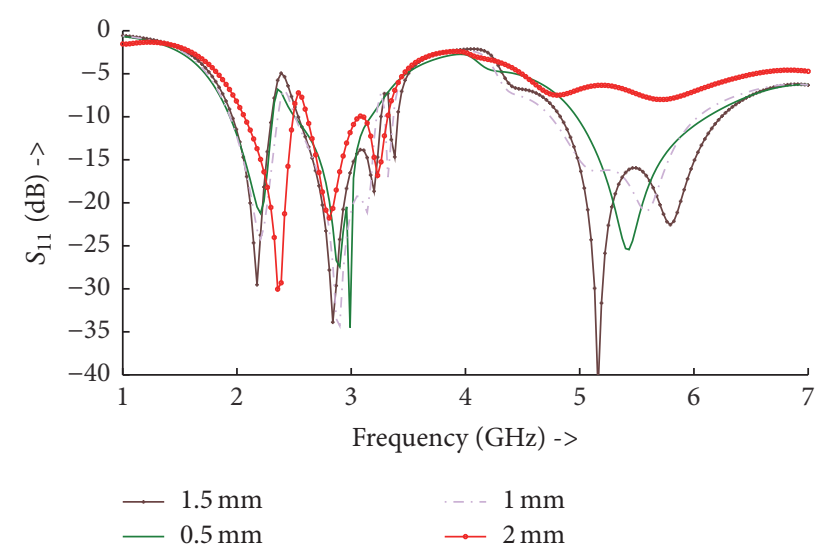

FIGURE 6: Reflection coefficient of different overlapping size.

coefficient is affected. So, the most optimum length chosen for the design remains $37 \mathrm{~mm}$, since its reflection coefficient and resonant frequency produced acceptable results.

3.3.3. Patch Width's Effect. Figure 8 shows three different widths of the patch $\left(W_{p}\right)$ that are simulated and compared with the width of the proposed antenna $\left(W_{p}=24 \mathrm{~mm}\right)$. When the patch width is $20 \mathrm{~mm}$, we observe that the three bandwidths are decreased. It is also noticed that, by increasing the width more than $24 \mathrm{~mm}$, the resonant frequency of $3.33 \mathrm{GHz}$ shifted to $4.4 \mathrm{GHz}$. So, in this case we keep the width of $24 \mathrm{~mm}$ as the optimum value.

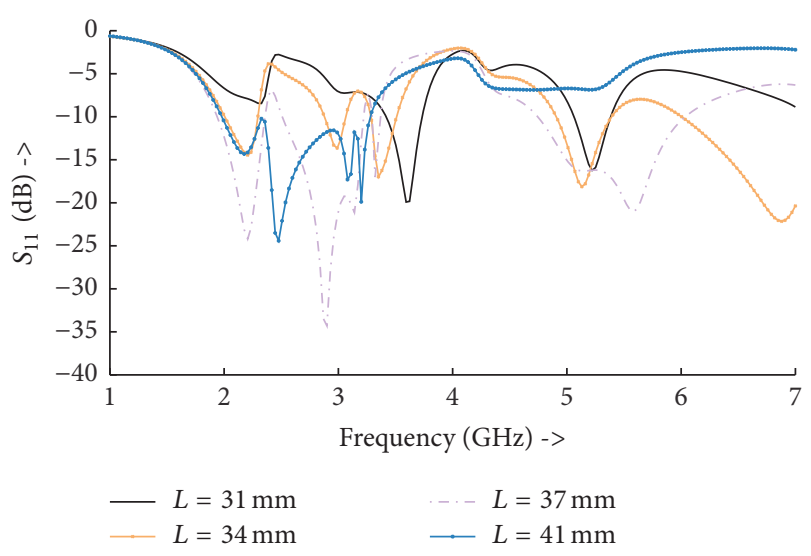

Figure 7: Reflection coefficient for different lengths of patch.

3.3.4. Shorting Pin Localization's Effect. The shorting pin localization is also studied (Figure 9). Three different localizations $(x)$ are compared in order to find out the optimum shorting pin localization. It has been observed that the localization of the shorting pin is very important to define. It can attenuate some frequency bands if it is not well chosen ( $5 \mathrm{~mm}$ and $15 \mathrm{~mm}$ ). Therefore, the optimized localization of the shorting pin that produced good reflection coefficient and the desired resonant frequency was kept at $x=25 \mathrm{~mm}$.

3.3.5. Feeding Pin Localization's Effect. Three different localizations of the feeding pin are simulated and compared to the 


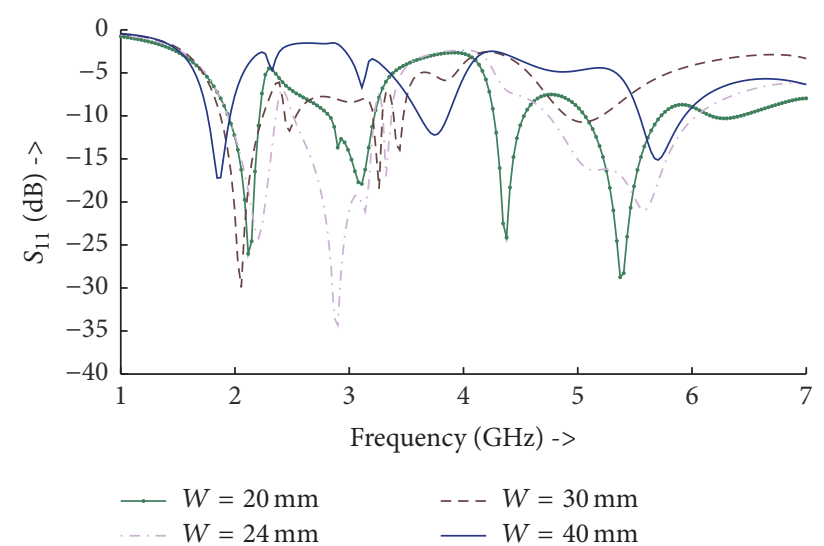

FIGURE 8: Reflection coefficient of different patch widths.

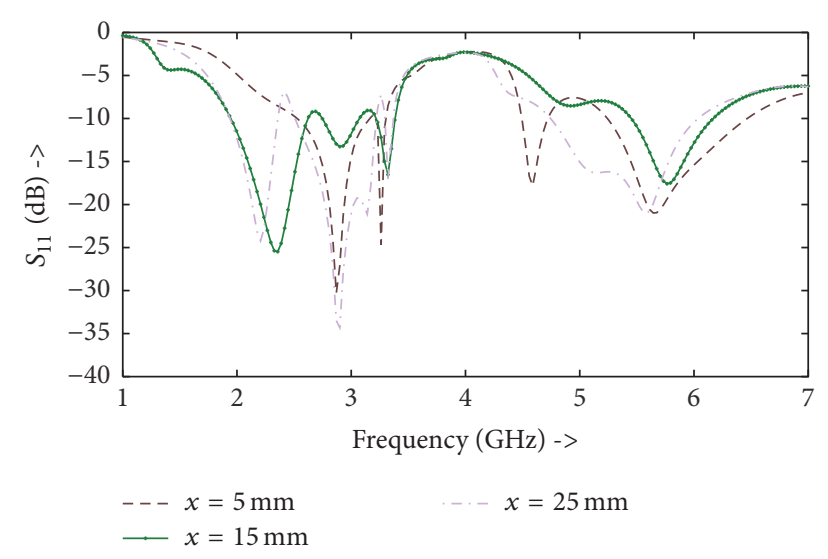

FIGURE 9: Reflection coefficient of different location of shorting pin.

proposed antenna feeding pin localization $(29 \mathrm{~mm})$ as shown in Figure 10. The results demonstrate that the localization of the shorting pin has an effect on the resonant frequency of the upper band and decreases the reflection coefficient of the lower and middle bands. The optimum localization is corresponding to $29 \mathrm{~mm}$.

3.3.6. Height Antenna's Effect. The height of the antenna $(h)$ is also an important parameter in terms of bandwidth and resonant frequency of the PIFA antenna. In Figure 11, we make the parametric study for different heights of the PIFA antenna; therefore, the best optimized height that produces good result should be selected.

Four different heights are simulated. The figure shows that when the height is increased, the bandwidth is increased but the reflection coefficient of the antenna is decreased. Therefore, the optimum height was $2.3 \mathrm{~mm}$.

The objective of this study is to find the most suitable PIFA parameters. The PIFA antenna geometry is optimized in terms of patch size, height of the antenna, and localization of both shorting and feeding pin. The results show that the use of overlaps between parallel cells improves the performance of the PIFA antenna in terms of bandwidth and reflection coefficient.

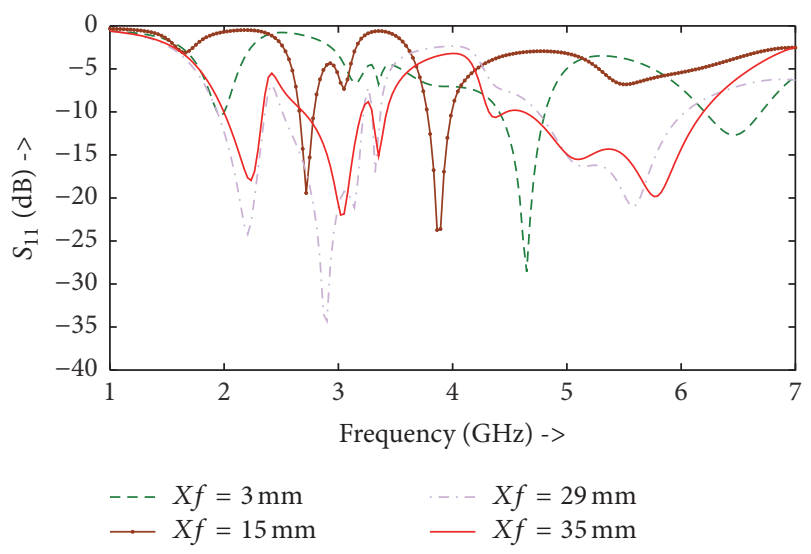

FIGURE 10: Reflection coefficient of different location of feeding pin.

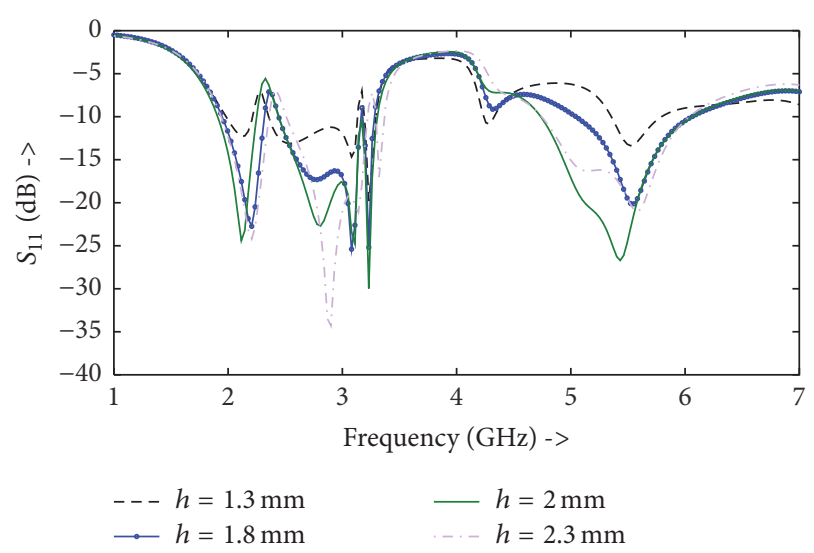

FIGURE 11: Reflection coefficient of different PIFA height.

3.4. Performances of the Optimized Design. The first approach by using gridded ground plane with particle swarm optimization leads to the size reduction and multiband option instead of single band antenna. The second approach by optimization of the overlap size between adjacent cells allows improving the antenna performance. The optimized PIFA antenna performances obtained by both methods are shown in Figures 12 and 13.

Triband PIFA antenna for UMTS2100, LTE2600, WIMAX, and WLAN bands with linear slots on the ground plane is investigated. The antenna resonance frequencies as obtained from the simulator HFSS are 2.18, 2.83, and $5.16 \mathrm{GHz}$ with reflection coefficients of $-29.5,-33.88$, and $-40.69 \mathrm{~dB}$, respectively (Figure 12 ). The bandwidths are $15.59 \%, 30.74 \%$, and $27.33 \%$ for the lower, middle, and upper bands, respectively. The reflection coefficients simulated by both CSTMWS and HFSS are proved to be identical.

The proposed antenna radiating nearly along the broadside direction has gained values of $2.67 \mathrm{~dB}, 1.80 \mathrm{~dB}$, and 7.12, respectively (Figure 13). Compared to the radiation pattern of a conventional PIFA antenna, the optimized design has a lower gain at the lower frequency bands. However, it has a higher gain at the upper band. The radiation efficiency is about $94 \%$. Therefore, this triband PIFA is good to be used for 


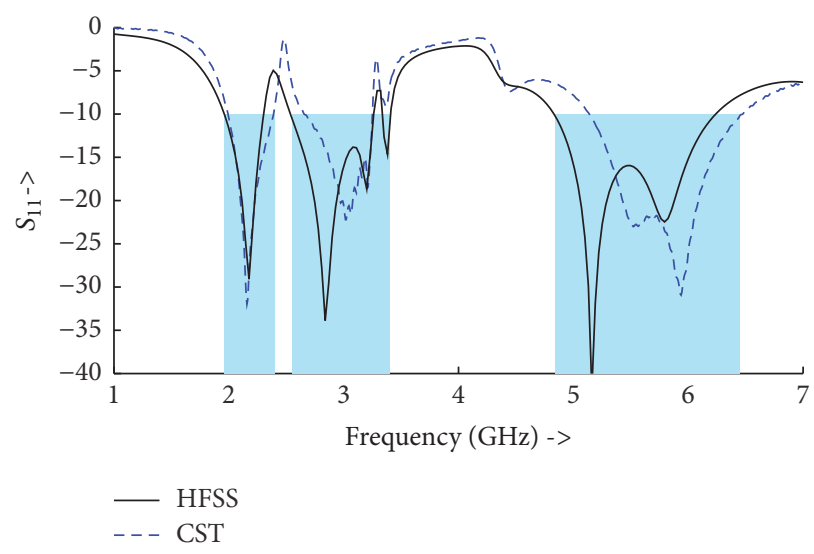

FIGURE 12: Reflection coefficient of the final optimized PIFA antenna.

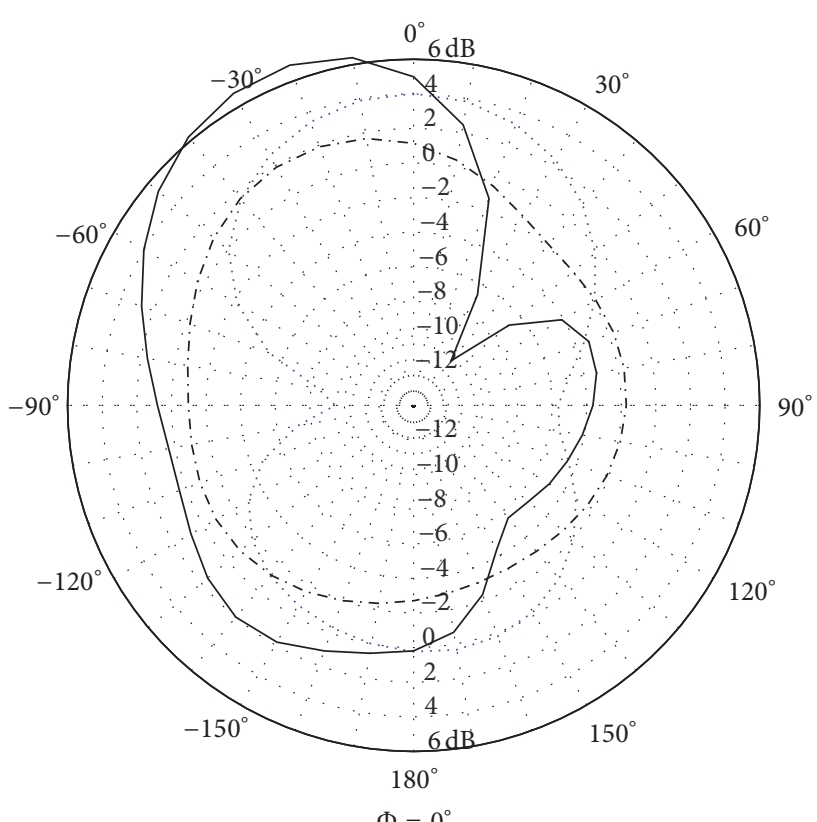

$f=2.18 \mathrm{GHz}$

- - $f=2.83 \mathrm{GHz}$

$-f=5.16 \mathrm{GHz}$

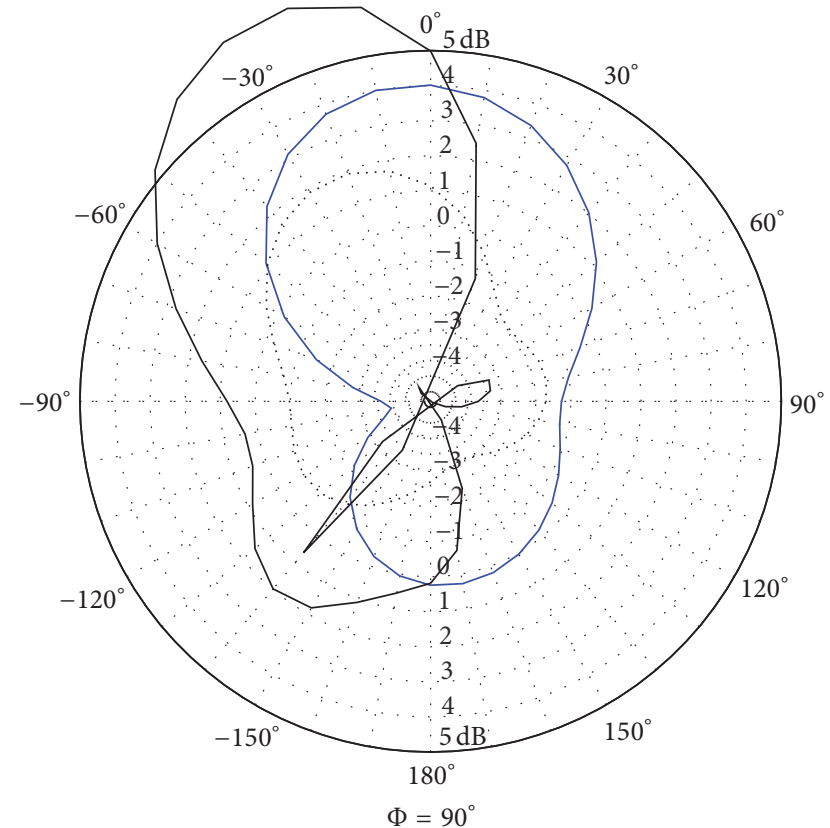

$f=2.18 \mathrm{GHz}$

$f=2.83 \mathrm{GHz}$

$-f=5.16 \mathrm{GHz}$

(a)

(b)

FIGURE 13: Simulated 2D radiation pattern for final PIFA antenna.

mobile communication application because of the reflection coefficient value, $S_{11}$, which has attained a desired value of $-10 \mathrm{~dB}$ at all operating frequencies.

\section{Conclusion}

Using gridded ground plane is a simple way to achieve a multiband antenna without modifying PIFA antenna geometry and increasing the handset volume. In this paper, the gridded ground plane was used for both size reduction and multiband operation.
The particle swarm optimization (PSO) was employed to find out the optimal geometry of the ground plane which respects the required objectives. The effect of the antenna parameters was studied. Acceptable performances were achieved for all bands of operation by controlling the overlapping size between parallel slits. The antenna gain and radiation patterns were found to be reasonable at all bands. This triband PIFA antenna required not only the multiband functionality but also other characteristics such as small size, light weight, omnidirectional radiation pattern, reasonable gain, and acceptable bandwidth. Since the mobile phone 
industry requires small handset terminals with internal antennas, the proposed technique in this research is a good way to reach these requirements.

\section{Competing Interests}

The authors declare that there is no conflict of interests regarding the publication of this paper.

\section{References}

[1] S. Lee and Y. Sung, "Reconfigurable PIFA with a parasitic strip line for a hepta-band WWAN/LTE mobile handset," IET Microwaves, Antennas and Propagation, vol. 9, no. 2, pp. 108-117, 2015.

[2] M. H. Seko and F. S. Correra, "A novel TRI-band planar inverted-F antenna for GSM/DCS/PCS operation in mobile handsets," Microwave and Optical Technology Letters, vol. 55, no. 4, pp. 821-825, 2013.

[3] L. Wakrim, S. Ibnyaich, and M. M. Hassani, "Optimization by genetic algorithm of a PIFA antenna parameters for Wifi application," in Proceedings of the International Conference on Multimedia Computing and Systems (ICMCS '14), pp. 1501-1505, Marrakesh, Morocco, April 2014.

[4] D.-G. Kang and Y. Sung, "Compact hexaband PIFA antenna for mobile handset applications," IEEE Antennas and Wireless Propagation Letters, vol. 9, pp. 1127-1130, 2010.

[5] B. Sanz-Izquierdo, J. Batchelor, and R. Langley, "Multiband printed PIFA antenna with ground plane capacitive resonator," Electronics Letters, vol. 40, no. 22, pp. 1391-1392, 2004.

[6] K.-J. Kim, S. Lee, B.-N. Kim, J.-H. Jung, and Y. J. Yoon, "Small antenna with a coupling feed and parasitic elements for multiband mobile applications," IEEE Antennas and Wireless Propagation Letters, vol. 10, pp. 290-293, 2011.

[7] H. Wang and M. Zheng, "An internal triple-band WLAN antenna," IEEE Antennas and Wireless Propagation Letters, vol. 10, pp. 569-572, 2011.

[8] H. Elsadek and D. M. Nashaat, "Multiband and UWB V-shaped antenna configuration for wireless communications applications," IEEE Antennas and Wireless Propagation Letters, vol. 7, pp. 89-91, 2008.

[9] W.-W. Lee and S. Hong, "A multiband and wideband antenna using RF switch for mobile application," Microwave and Optical Technology Letters, vol. 57, no. 6, pp. 1491-1494, 2015.

[10] C.-T. Lee and S.-W. Su, "Very-low-profile, 2.4/5.2/5.8-GHz, triband WLAN antenna for laptop-tablet computer with complete metal cover," Microwave and Optical Technology Letters, vol. 58, no. 1, pp. 225-233, 2016.

[11] Y. Chawanonphithak and C. Phongcharoenpanich, "Design of triple-band antenna using S-shaped patch fed by cross strip line for WLAN and WiMAX applications," IEEJ Transactions on Electrical and Electronic Engineering, vol. 10, no. 5, pp. 491-497, 2015.

[12] M. Taghadosi, L. Albasha, N. Qaddoumi, and M. Ali, "Miniaturised printed elliptical nested fractal multiband antenna for energy harvesting applications," IET Microwaves, Antennas and Propagation, vol. 9, no. 10, pp. 1045-1053, 2015.

[13] C. Puente, J. Romeu, R. Pous, X. Garcia, and F. Benitez, "Fractal multiband antenna based on the Sierpinski gasket," Electronics Letters, vol. 32, no. 1, pp. 1-2, 1996.

[14] W.-C. Weng and C.-L. Hung, "An H-fractal antenna for multiband applications," IEEE Antennas and Wireless Propagation Letters, vol. 13, pp. 1705-1708, 2014.
[15] L. Wakrim, S. Ibnyaich, and M. M. Hassani, "Dual band PIFA antenna for WiMAX application obtained by using gridded ground plane and genetic algorithm," in Proceedings of the MacroTrend Conference on Physical and Life Sciences, Paris, France, December 2014.

[16] L. Wakrim, S. Ibnyaich, and M. M. Hassani, "Dual band antenna by combining PIFA and fragmented ground plane using genetic algorithm," in Proceedings of the 2nd Workshop on Smart Cities, Agadir, Morocco, May 2015.

[17] N. Kumar and G. Saini, "A multiband Pifa with slotted ground plane for personal communication handheld devices," International Journal of Engineering Research and Development, vol. 7, no. 11, pp. 70-74, 2013.

[18] M. Shihab, Y. Najjar, N. Dib, and M. Khodier, "Design of nonuniform circular antenna arrays using particle swarm optimization," Journal of Electrical Engineering, vol. 59, no. 4, pp. 216220, 2008.

[19] W. T. Li, X. W. Shi, and Y. Q. Hei, "An improved particle swarm optimization algorithm for pattern synthesis of phased arrays," Progress in Electromagnetics Research, vol. 82, pp. 319-332, 2008.

[20] W.-C. Liu, "Design of a multiband CPW-fed Monopole antenna using a particle swarm optimization approach," IEEE Transactions on Antennas and Propagation, vol. 53, no. 10, pp. 32733279, 2005.

[21] Z. Bayraktar, P. L. Werner, and D. H. Werner, "The design of miniature three-element stochastic Yagi-Uda arrays using particle swarm optimization," IEEE Antennas And Wireless Propagation Letters, vol. 5, no. 1, pp. 22-26, 2006.

[22] L. Wakrim, S. Ibnyaich, and M. M. Hassani, "The study of the ground plane effect on a multiband PIFA antenna by using genetic algorithm and particle swarm optimization," Journal of Microwaves, Optoelectronics and Electromagnetic Applications, vol. 15, no. 4, pp. 293-308, 2016. 

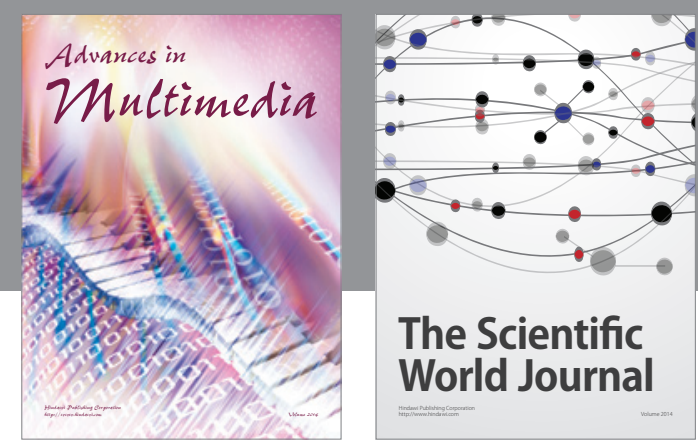

The Scientific World Journal
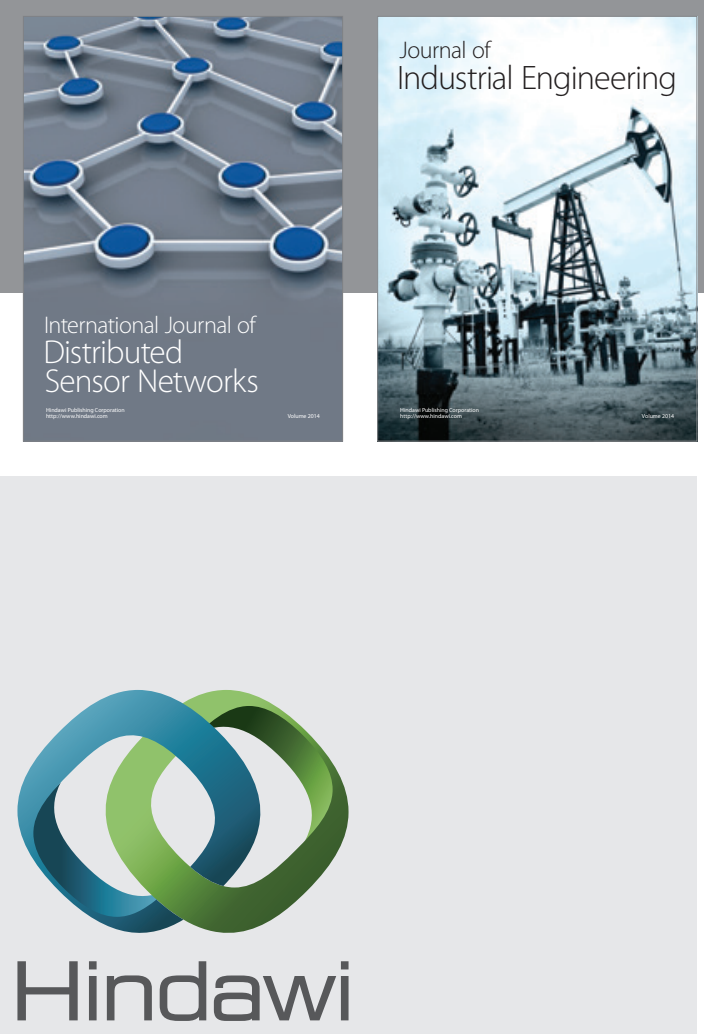

Submit your manuscripts at

https://www.hindawi.com

\section{Computer Networks} and Communications
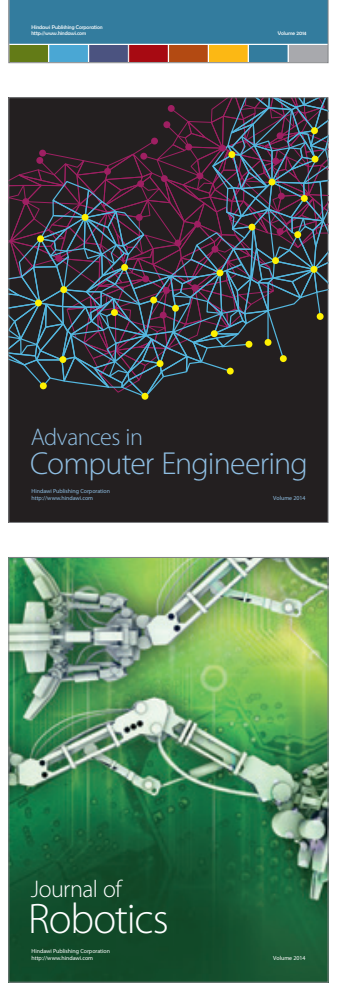
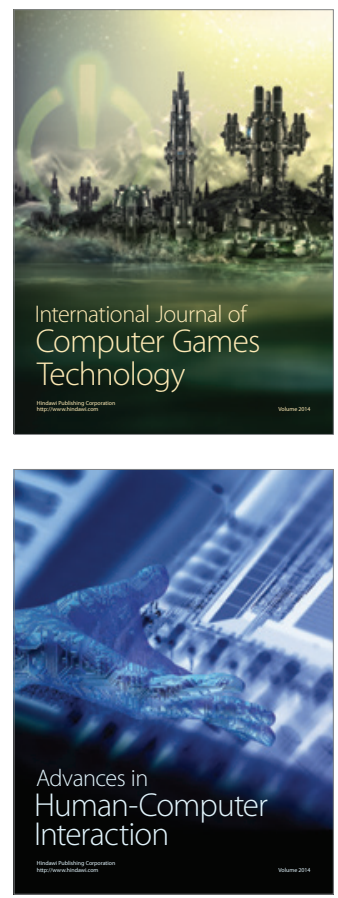
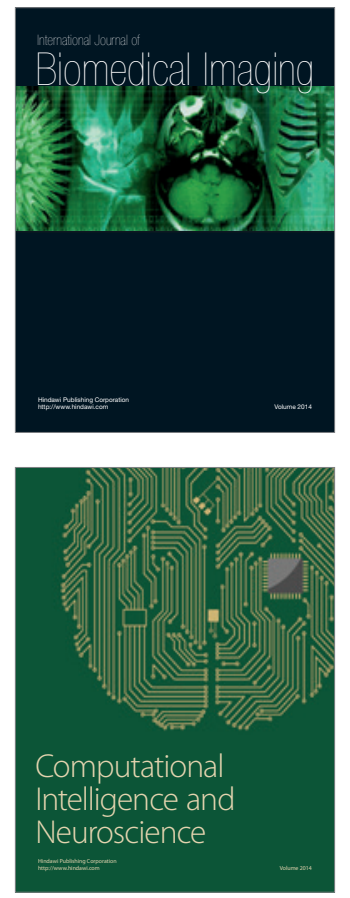
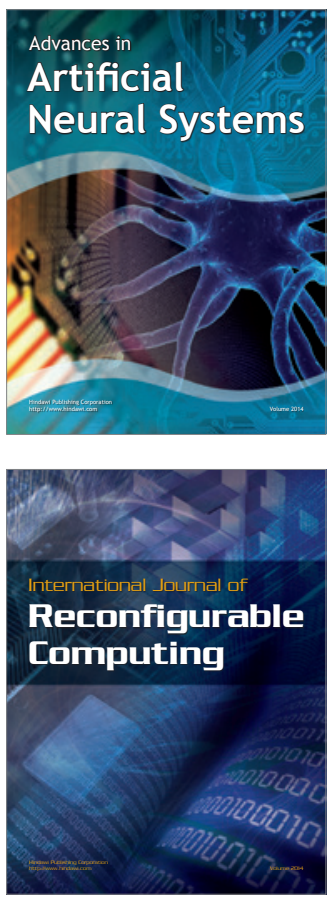
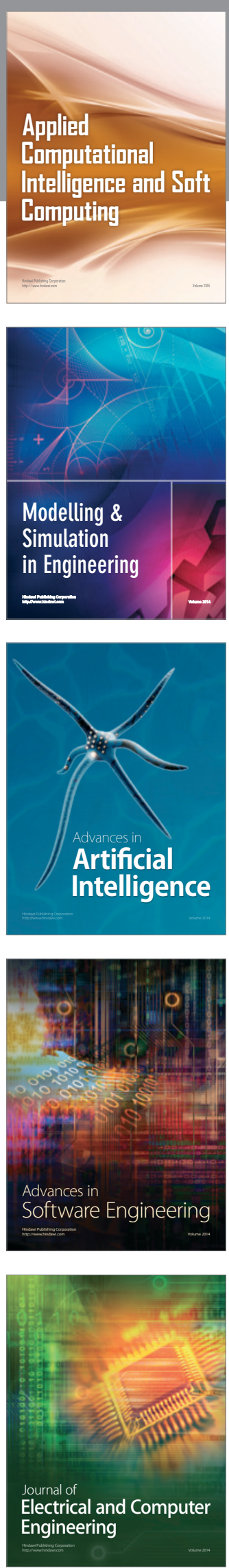